\title{
Effects of different preoperative biliary drainage methods for resected malignant obstruction jaundice on the incidence rate of implantation metastasis: A meta-analysis
}

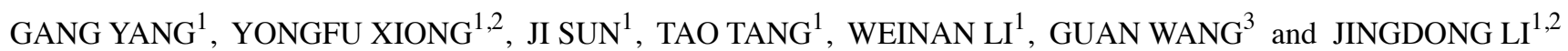 \\ ${ }^{1}$ Department of Hepatocellular Surgery, Affiliated Hospital of North Sichuan Medical College, Nanchong, Sichuan 637007; \\ ${ }^{2}$ Institute of Hepato-Biliary-Intestinal Disease, North Sichuan Medical College, Nanchong, Sichuan 637000; \\ ${ }^{3}$ Physical Examination Center, Affiliated Hospital of North Sichuan Medical College, Nanchong, Sichuan 637007, P.R. China
}

Received December 4, 2019; Accepted May 27, 2020

DOI: $10.3892 / \mathrm{ol} .2020 .11767$

\begin{abstract}
The aim of the present study was to compare the effects of percutaneous transhepatic biliary drainage (PTBD) and endoscopic biliary drainage (EBD) for resected malignant obstruction jaundice (MOJ) on the incidence rate of implantation metastasis. Databases including PubMed, EMbase, Web of Science and Cochrane Library were utilized. With reference to literature reported until January 2019, controlled clinical trials were designed to compare the effects of PTBD and EBD for MOJ on the incidence rate of implantation metastasis. Subsequently, odds ratio (OR) with $95 \%$ confidence interval (CI) was calculated with Review Manager 5.3.0 software. A total of 10 studies were enrolled in this meta-analysis, including 1,085 cases in the PTBD group and 1,379 cases in the EBD group. The results revealed that there was a significant difference in the incidence rate of implantation metastasis between the PTBD group and EBD group (OR=0.35, 95\% CI: 0.23-0.53, $\mathrm{P}<0.00001)$. Subgroup analysis revealed that the incidence rates of both catheter-related implantation metastasis and peritoneal metastasis were lower in the EBD group $(\mathrm{OR}=0.23,95 \% \mathrm{CI}$ : 0.12-0.44, $\mathrm{P}<0.00001 ; \mathrm{OR}=0.47,95 \%$ CI: $0.31-0.74, \mathrm{P}=0.0008$, respectively), and the advantage of EBD was demonstrated in perihilar cholangiocarcinoma, distal cholangiocarcinoma and pancreatic carcinoma $(\mathrm{OR}=0.35,95 \% \mathrm{CI}$ : 0.17-0.74, $\mathrm{P}=0.006$; $\mathrm{OR}=0.32,95 \% \mathrm{CI}: 0.17-0.60, \mathrm{P}=0.0005 ; \mathrm{OR}=0.27,95 \%$ CI: $0.19-0.40, \mathrm{P}<0.00001$, respectively). In conclusion, this meta-analysis revealed the appropriate choice of preoperative biliary drainage for resected MOJ. The application of EBD reduced the incidence rate of implantation metastasis, however
\end{abstract}

Correspondence to: Jingdong Li, Department of Hepatocellular Surgery, Affiliated Hospital of North Sichuan Medical College, 63 Wenhua Road, Nanchong, Sichuan 637007, P.R. China E-mail: zhujixie19670314@163.com

Key words: malignant obstruction jaundice, percutaneous transhepatic biliary drainage, endoscopic biliary drainage, meta-analysis more evidence is required from future studies, to confirm the results.

\section{Introduction}

Malignant obstructive jaundice (MOJ) is caused by intrahepatic and extrahepatic bile duct obstruction due to malignant obstructive tumor invasion or oppression, which is mainly manifested by hyperbilirubinemia and scleral yellow staining (1). Obstruction can cause a series of pathophysiological disorders of the organism, including bile duct dilation, increased capillary bile duct permeability, the flowing of bile composition into blood and the reverse inflow of bile into the blood and lymph, which is the leading cause of death (2).

The main treatment for malignant biliary obstruction is resection and drainage (3). However, due to the malignancy of the tumor itself and its special anatomical structure, most patients have lost the opportunity of radical surgery at the time of diagnosis. Therefore, $90 \%$ of patients diagnosed with malignant biliary obstruction can only benefit from palliative resection (4). In addition, effective preoperative drainage can significantly improve the prognosis of patients undergoing radical surgery (4). The harm of malignant biliary obstruction is not only the tumor itself but also the organ damage caused by hyperbilirubinemia. Therefore, effective biliary drainage is an important treatment for patients in the advanced stage. Reducing jaundice can protect liver and kidney function, improve quality of life and prolong survival (5). Tibble et al (6), have revealed that due to the delayed diagnosis, the resectability of high biliary tract tumors is only 15-20\%. Therefore, removing obstruction, unobstructed drainage and rapid and effective reduction of jaundice is the key to treatment. According to bile discharge methods, preoperative biliary drainage can be divided into internal drainage and external drainage, and based on the drainage pathway, it can be divided into percutaneous transhepatic biliary drainage (PTBD) and endoscopic biliary drainage (EBD) (7). However, the method of preoperative biliary drainage is still controversial. Some scholars believe that PTBD is prone to complications such as pancreatitis, cholangitis, biliary perforation, biliary bleeding and stent displacement (8). However, other studies have found 
that compared with EBD, PTBD causes less surgical trauma, fewer complications and faster bilirubin decrease (9).

At present, the specific selection of preoperative biliary drainage methods for malignant obstructive jaundice has not been determined. In this meta-analysis, therefore, the advantages and disadvantages of these two drainage methods were analyzed from the perspective of tumor implantation metastasis after drainage. In addition, all included controlled clinical trials were designed to compare the incidence rate of implantation metastasis between EBD and PTBD in preoperative biliary drainage of $\mathrm{MOJ}$, in order to provide references for clinical application.

\section{Materials and methods}

Search strategy. PubMed (https://pubmed.ncbi.nlm.nih. gov/?term=), Embase (https://www.embase.com/), Web of Science (www.isiknowledge.com/) and Cochrane Library (https://www.cochranelibrary.com/) were utilized. Literature published from the database establishment to January 2019 as well as similar literature and references attached to the search results were consulted. The retrieval strategy was 'malignant obstruction jaundice' (Title/Abstract) or 'perihilar cholangiocarcinoma' (Title/Abstract) or 'distal cholangiocarcinoma' (Title/Abstract) or 'pancreatic cancer' (Title/Abstract) and 'preoperative biliary drainage' (Title/Abstract) or 'percutaneous transhepatic biliary drainage' (Title/Abstract) or 'endoscopic biliary drainage' (Title/Abstract) and 'seeding metastasis' (Title/Abstract) or 'peritoneal metastasis' (Title/Abstract).

Inclusion and exclusion criteria. The inclusion criteria were as follows: i) Clinical study of preoperative biliary drainage in patients with MOJ; ii) EBD and PTBD were preoperative biliary drainage methods; iii) The incidence rate of implantation metastasis was the main objective of the study; iv) The methodology used in the study was reliable; and v) The data provided were complete and accurate. The exclusion criteria were as follows: i) Irrelevant or in vitro experiments; ii) Case report, review, letter or conference paper; or iii) Repeated reports. If the data of a center were published numerous times, the most recently published data would be selected. If a study was reported more than once, the data with the longest follow-up time would be used.

Data extraction and quality assessment. Two reviewers independently read the literature titles and abstracts according to the aforementioned inclusion and exclusion criteria and after excluding the studies that evidently did not meet the inclusion criteria, the full text of the remaining studies was read to determine whether they met the inclusion criteria and extract relevant data. In case of disagreement, inclusion was determined by a third reviewer. The extracted contents included: i) General information: Title, first author, publication date and literature source; ii) Research characteristics: Grouping methods and included cases of the subjects; iii) Outcome index (incidence rate of implantation metastasis); and iv) Information related to literature quality assessment.

Two reviewers evaluated the quality of the included studies according to the Newcastle Ottawa scale (NOS) (10) and the third reviewer evaluated the study when the scores were inconsistent. The full score of the NOS is 9 points, and the evaluation criteria include the selection, comparability and outcome of the cohort studies. Selection indicates the selection of cases and controls with a total score of 4 , including the typicality of the exposed cohorts (1 score), non-exposed cohorts from the same community (1 score), reliable determination of exposure (1 score), and the unpresented outcomes at the beginning of the study (1 score). Comparability indicates the comparability of cases and control group with a total score of 2 , including the control of the most important confounders (1 score) and the control of other confounders (1 score). Outcome indicates methods of investigation and assessment of exposure with a total score of 3 , including independent blind evaluation (1 score), adequate follow-up time (1 score) and full follow-up of all subjects (1 score). The study with a score equal to or greater than 6 points is divided into a high-quality study.

Intervention measures and observed indicators. Intervention measures were as follows: PTBD, percutaneous transhepatic biliary drainage, including internal drainage and external drainage, EBD, endoscopic biliary drainage, including internal drainage and external drainage.

Observed indicators were as follows: Implantation metastasis, (a) The area through which the catheter passed, including the skin poke and the abdominal chest wall layer; (b) Right pleural implantation metastasis; (c) Peritoneal implantation metastasis; (d) Intrahepatic metastasis; and (e) Surgical success rate. Deaths in hospital and severe postoperative complications (such as infection) were considered surgical failures. Catheter-related implantation metastasis included (a) (b) (d).

Statistical analysis. Meta-analysis was performed using the RevMan5.3.0 software provided by the Cochrane Collaboration. Heterogeneity between studies was analyzed. $\mathrm{P}>0.05$ or $\mathrm{I}^{2}<50 \%$ indicated that there was a small possibility of heterogeneity among studies, and the fixed effect models were used. Conversely, $\mathrm{P}<0.05$ or $\mathrm{I}^{2}>50 \%$ indicated that there was heterogeneity among the studies, and the random effect models were used. Enumeration data were analyzed according to the odds ratio (OR), and the $95 \%$ confidence interval $(95 \% \mathrm{CI})$ was calculated. The funnel plot was drawn by RevMan5.3.0 software to determine whether there were any publication biases.

\section{Results}

Study selection and study characteristics. Ten studies were included (9,11-19), including six for hilar cholangiocarcinoma, two for distal cholangiocarcinoma, and two for pancreatic carcinoma. The retrieval and screening processes are presented in Fig. 1. Baseline data of the included literature are presented in Table I. All the studies included PTBD and EBD schemes, all of which were retrospective cohort studies with NOS scores ranging from 7 to 8 points, as presented in Table II.

Comparison of the effects of EBD and PTBD on the overall incidence rate of implantation metastasis in resected MOJ. A total of ten studies reported the comparison of the incidence rate of implantation metastasis. The results of the heterogeneity 


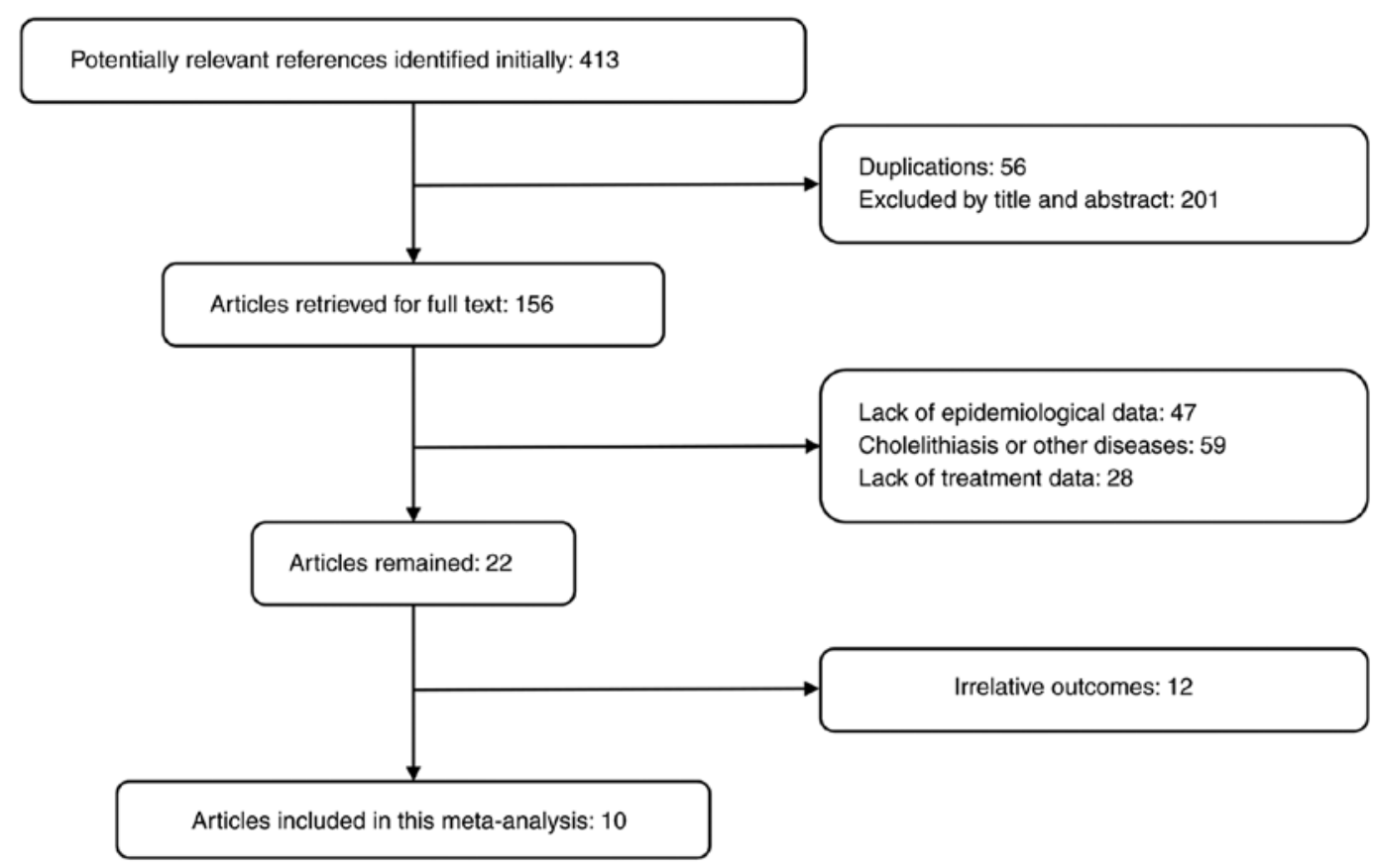

Figure 1. Study flow and selection diagram.

\begin{tabular}{|c|c|c|c|c|c|c|c|c|c|c|}
\hline Study or subgroup & \multicolumn{2}{|c|}{ EBD } & \multicolumn{2}{|c|}{ PTBD } & Weight & \multicolumn{2}{|l|}{ Odds ratio } & \multicolumn{2}{|c|}{$\begin{array}{c}\text { Odds ratio } \\
\mathrm{M}-\mathrm{H}, \text { Random, } 95 \% \mathrm{Cl}\end{array}$} & \\
\hline Higuchi 2017 & 11 & 76 & 31 & 87 & $13.0 \%$ & $0.31[0.14,0.66]$ & & & & \\
\hline Hirano 2014 & 3 & 74 & 20 & 67 & $7.4 \%$ & $0.10[0.03,0.35]$ & & & & \\
\hline Hwang 2012 & 0 & 122 & 7 & 231 & $2.0 \%$ & $0.12[0.01,2.16]$ & & & & \\
\hline Kawakami 2011 & 0 & 80 & 3 & 48 & $1.8 \%$ & $0.08[0.00,1.60]$ & & & & \\
\hline Komaya 2016 & 13 & 187 & 38 & 189 & $14.7 \%$ & $0.30[0.15,0.58]$ & & & & \\
\hline Komaya 2017 & 25 & 150 & 45 & 165 & $16.6 \%$ & $0.53[0.31,0.92]$ & & & & \\
\hline Miura 2017 & 2 & 63 & 1 & 25 & $2.6 \%$ & $0.79[0.07,9.09]$ & & & & \\
\hline Murakami 2015 & 12 & 73 & 8 & 20 & $9.1 \%$ & $0.30[0.10,0.88]$ & & & & \\
\hline Uemura 2015 & 63 & 407 & 67 & 166 & $19.0 \%$ & $0.27[0.18,0.41]$ & & & & \\
\hline Wiggers 2015 & 25 & 147 & 14 & 87 & $13.9 \%$ & $1.07[0.52,2.19]$ & & & & \\
\hline Total $(95 \% \mathrm{Cl})$ & & 1379 & & 1085 & $100.0 \%$ & $0.35[0.23,0.53]$ & & & & \\
\hline Total events & 154 & & 234 & & & & & & & \\
\hline $\begin{array}{l}\text { Heterogeneity: } \text { Tau }^{2} \\
\text { Test for overall effec }\end{array}$ & $\begin{array}{l}.20 ; \mathrm{Chi}^{2} \\
=4.91(\mathrm{~F}\end{array}$ & $\begin{array}{l}=19.2 \\
\partial<0.0\end{array}$ & $\begin{array}{l}0, \mathrm{df}=9( \\
0001)\end{array}$ & $(P=0.0$ & $2) ; 1^{2}=53^{\circ}$ & & 0.01 & $\begin{array}{l}0.1 \\
\text { Favours [PTBD] }\end{array}$ & $\begin{array}{cc}1 & 10 \\
\text { Favours [EBD }\end{array}$ & 100 \\
\hline
\end{tabular}

Figure 2. Forest plot of the incidence rate of implantation metastasis in resected MOJ.

analysis $\left(\mathrm{I}^{2}=53 \%, \mathrm{P}=0.02\right)$ demonstrated that there was heterogeneity among the studies, and the random effect model was used for analysis. Meta-analysis results revealed that the overall incidence rate of implantation metastasis in the EBD and PTBD groups was $11.2 \%$ (154/1379) and $21.2 \%(234 / 1085)$, respectively, with statistically significant differences between the two groups $(\mathrm{OR}=0.35,95 \% \mathrm{CI}$ : 0.23-0.53, $\mathrm{P}<0.00001$; Fig. 2).

Comparison of the effects of EBD and PTBD on the incidence rate of different types of implantation metastases in resected MOJ. Implantation metastases can be divided into peritoneal metastasis and catheter-related implantation metastasis. The subgroup analysis results revealed that the incidence rates of catheter-related implantation metastasis and peritoneal implantation metastasis in the EBD and PTBD groups were $2.1 \%(26 / 1230)$ vs. $6.4 \%(69 / 1078)$ and
$10.5 \%(116 / 1101)$ vs. $19.3 \%(138 / 716)$, respectively, and the differences were statistically significant $(\mathrm{OR}=0.23,95 \% \mathrm{CI}$ : $0.12-0.44, \mathrm{P}<0.00001$; and $\mathrm{OR}=0.47,95 \% \mathrm{CI}: 0.31-0.74$, $\mathrm{P}=0.0008$; Fig. 3).

Comparison of the effects of EBD and PTBD on the incidence rate of implantation metastasis in different parts of resected MOJ. Obstructive jaundice can be caused by hilar cholangiocarcinoma, distal cholangiocarcinoma and pancreatic carcinoma. The results of subgroup analysis revealed that the incidence rate of implantation metastasis in hilar cholangiocarcinoma, distal cholangiocarcinoma and pancreatic carcinoma of the EBD and PTBD groups were $9.7 \%(64 / 649)$ vs. $17.5 \%(120 / 685), 6 \%(15 / 250)$ vs. $18.2 \%$ $(39 / 214), 15.6 \%(75 / 480)$ vs. $40.3 \%$ (75/186), respectively, and the differences were statistically significant $(\mathrm{OR}=0.35$, 95\% CI: $0.17-0.74, \mathrm{P}=0.006 ; \mathrm{OR}=0.32,95 \% \mathrm{CI}: 0.17-0.60$, 


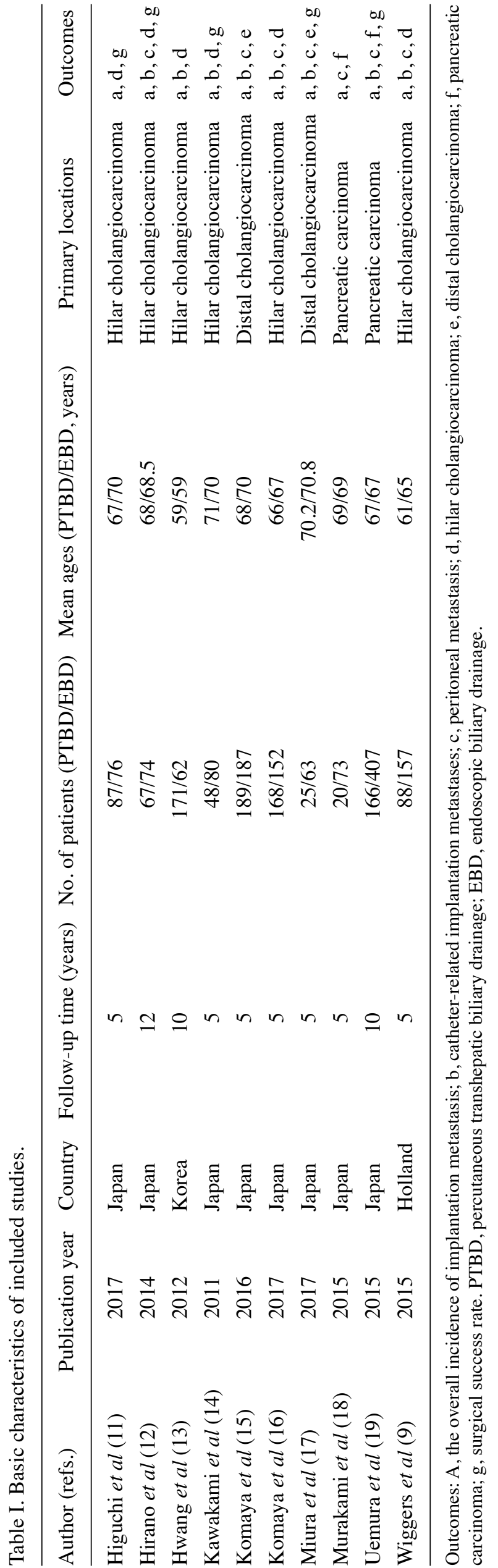

$\mathrm{P}=0.0005$; and $\mathrm{OR}=0.27,95 \% \mathrm{CI}: 0.19-0.40, \mathrm{P}<0.00001$; Fig. 4).

Comparison of the effects of EBD and PTBD on the surgical success rate in resected MOJ. A total of 5 studies reported the comparison of the surgical success rate. The heterogeneity analysis results $\left(\mathrm{I}^{2}=43 \%, \mathrm{P}=0.14\right)$ demonstrated that there was no obvious heterogeneity among the studies, and fixed effect model analysis was used. Meta-analysis results revealed that the surgical success rate of the EBD and the PTBD groups were 96.6\% (676/700) and 94.6\% (372/393), respectively, and there was no statistically significant difference between the two groups (OR=1.52, 95\% CI: 0.82-2.82, $\mathrm{P}=0.19$; Fig. 5).

Publication bias analysis. A funnel plot was used to analyze the incidence rate of implantation metastasis in the EBD and PTBD groups, and the results revealed that funnel plot was basically symmetrical, indicating that publication bias had little impact on meta-analysis results (Fig. 6).

\section{Discussion}

Implantation metastasis is an important metastatic route for abdominal malignancy and invasive procedures, while preoperative biliary drainage may directly or indirectly increase the risk of implantation metastasis (20). In this meta-analysis, the incidence rate of implantation metastasis in the application of two common preoperative biliary drainage methods was analyzed, and it was found that the incidence rate of implantation metastasis in EBD was lower than that in PTBD for resected MOJ.

Surgery remains the most effective treatment for resected hepatobiliary and pancreatic malignancies (21). For malignant hepatobiliary and pancreatic tumors with obstructive jaundice, how to effectively remove biliary obstruction and reduce hyperbilirubinemia is of great importance to improve the success rate of surgery. However, a growing body of studies have found that preoperative biliary drainage (PBD) cannot prolong the survival of MOJ patients, and it extends the length of hospital stay and increases the postoperative complications (22). Nevertheless, the US (23), European (24) and Japanese (25) guidelines recommend appropriate PBD for patients with MOJ. However, there remains controversy in the international hepatobiliary and pancreatic community about which drainage method to select: The European and American guidelines recommend PTBD, while the Japanese guidelines strongly recommend EBD. Compared with EBD, PTBD surgery is simple and easy to perform. The latest meta-analysis confirmed that PTBD was more effective in reducing postoperative complications than $\mathrm{EBD}(26.5 \%$ vs. $44.3 \%, \mathrm{P}=0.0009)$ (26). As supporters of the EBD procedure, the Japanese consider implantation metastasis as the most important factor (27).

Implantation metastasis is one of the distant metastatic pathways of abdominal malignant tumors. It can be divided into direct dissemination and hematogenous or lymphatic dissemination according to the metastatic pathway, and into thoracoperitoneal implantation and body wall implantation according to implantable location. Hepatobiliary and 


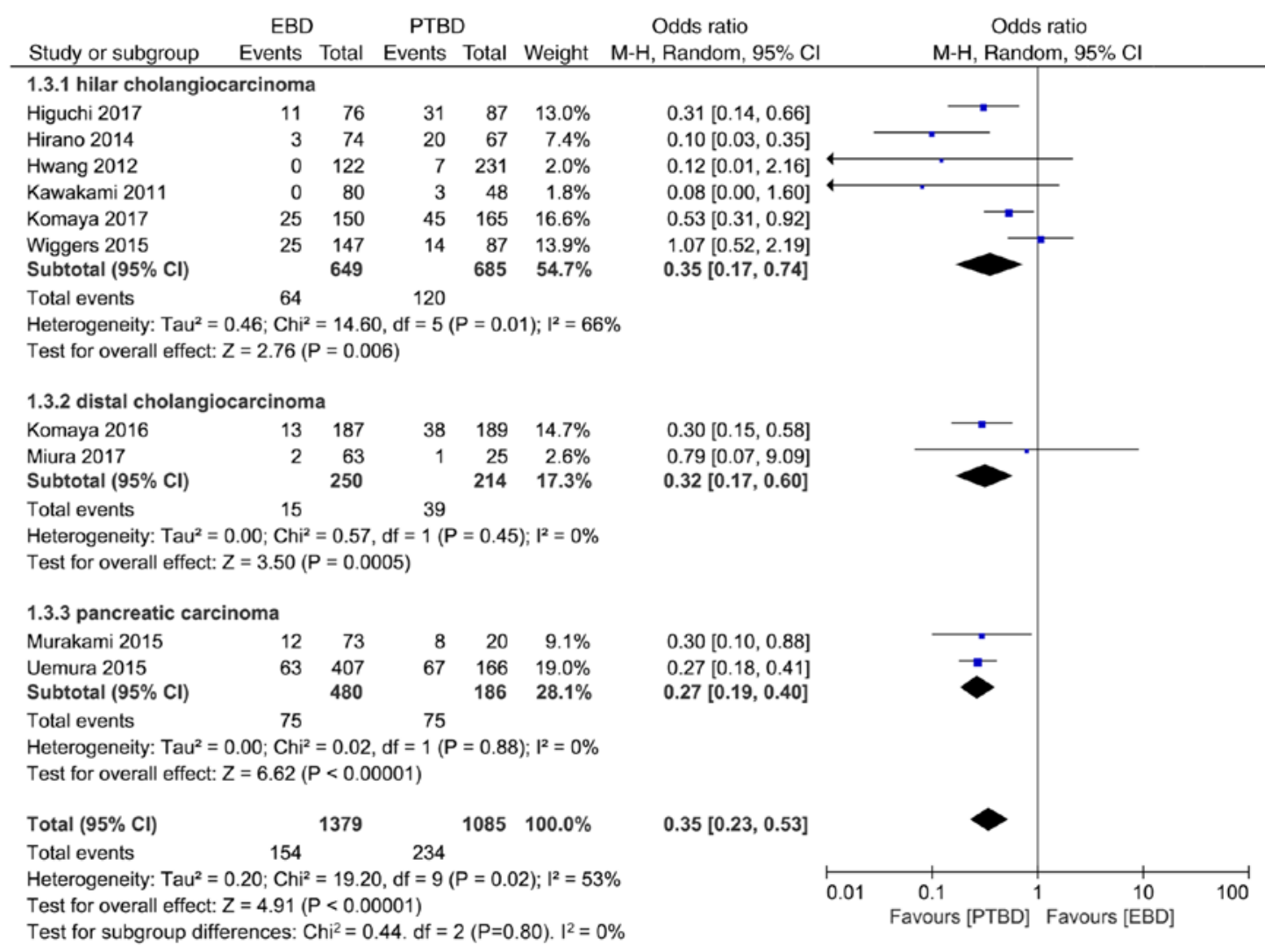

Figure 4. Forest plot of the incidence rate of implantation metastasis in different parts of resected MOJ.

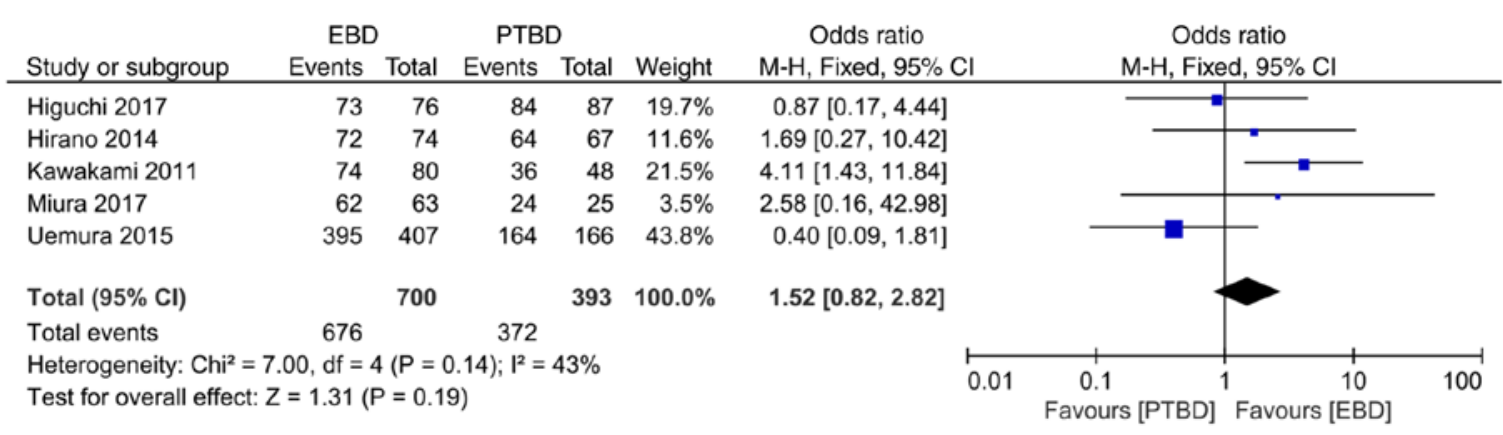

Figure 5. Forest plot of the surgical success rate in resected MOJ.

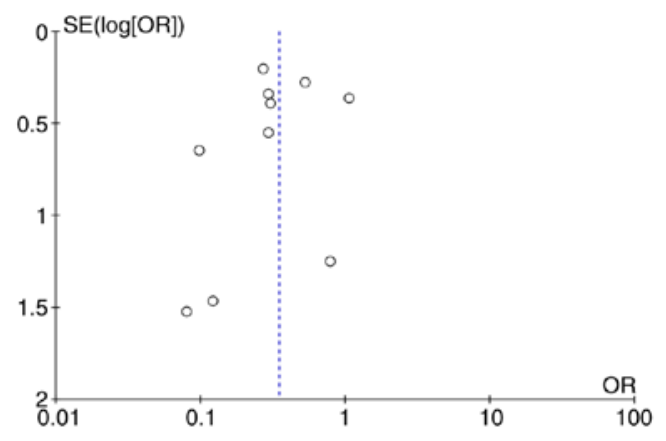

Figure 6. Funnel plot for publication bias assessment.

the risk of catheter-related implantation metastasis $(4.3 \%$ vs. $0.6 \%, \mathrm{P}<0.0001)$. In conclusion, the prevalence and poor prognosis of implantation metastasis after PTBD surgery indicates that attention must be paid to the problem of implantation metastasis after PBD surgery.

Although this meta-analysis studies the effect of drainage in MOJ, drainage is not necessary for MOJ in some cases. Some scholars theorize that pancreaticoduodenectomy can be performed without cholangitis in the presence of obstructive jaundice (28). All the ten studies included in this study were retrospective cohort studies that were clearly grouped, and no selective results were reported. Although literature retrieval and strict inclusion criteria were utilized in the present study, there are still limitations. In spite of the retrieval procedure adopted widely, some data such as supplements, conference papers, and certain grey literature were unavailable. Furthermore, as the original data of the included studies were not sufficient, the meta-analysis could only comment on relevant indicators, thus potential publication bias cannot be avoided. In addition, a large number 
of retrospective cohort studies were included in this study, lacking large sample, multi-center randomized controlled studies. There was no clear definition of MOJ implantation metastasis. Intrahepatic metastasis belongs to the implantation metastasis related to PBD of pancreatic carcinoma, but it is controversial for hilar cholangiocarcinoma and distal cholangiocarcinoma (29). The categories of implantable abdominal metastasis are different, and the definitions of abdominal invasion, abdominal dissemination and abdominal metastasis are confounding. The PBD schemes included in the studies were different, and the PBD including PTBD and EBD technologies used varied among hospitals, resulting in heterogeneity of the studies, which may affect the evidence strength and credibility of the results of this meta-analysis. In addition, there was no significant difference in the surgical success rate between the two groups. Due to the limitation of the original research, there is a lack of relevant research in western countries. Therefore, more studies in western countries are expected to be carried out to draw more convincing conclusions.

In conclusion, this meta-analysis indicated that the incidence rate of implantation metastasis in EBD was lower than that in PTBD for resected MOJ. However, it should be noted that at present, sufficient evidence-based medicine is still lacking. In view of the lack of multi-center randomized controlled studies with a large sample size and the limitations of the literature quality, the aforementioned results should be confirmed by future studies.

\section{Acknowledgements}

Not applicable.

\section{Funding}

The present study was funded by the Project of the Department of Education, Sichuan Province (grant no. 16TDD00025).

\section{Availability of data and materials}

All data generated or analyzed during this study are included in this published article.

\section{Authors' contributions}

GY, YX, JL and JS collected the data. TT, WL and GW analyzed the data. GY and JL prepared and wrote the manuscript. All authors read and approved the final manuscript.

\section{Ethics approval and consent to participate}

Not applicable.

\section{Patient consent for publication}

Not applicable.

\section{Competing interests}

The authors declare that they have no competing interests.

\section{References}

1. Chandrashekhara SH, Gamanagatti S, Singh A and Bhatnagar S: Current status of percutaneous transhepatic biliary drainage in palliation of malignant obstructive jaundice: A review. Indian J Palliat Care 22: 378-387, 2016.

2. Xu X, Li J, Wu J, Zhu R and Ji W: A systematic review and meta-analysis of intraluminal brachytherapy versus stent alone in the treatment of malignant obstructive jaundice. Cardiovasc Intervent Radiol 41: 206-217, 2018.

3. Lorenz JM: Management of malignant biliary obstruction. Semin Intervent Radiol 33: 259-267, 2016.

4. Fukasawa M, Takano S, Shindo H, Takahashi E, Sato T and Enomoto N: Lorenz JM. Management of malignant biliary obstruction. Clin J Gastroenterol 10: 485-490, 2017.

5. Hucl T: Malignant biliary obstruction. Cas Lek Cesk 155: 30-37, 2016 (In Czech).

6. Tibble JA and Cairns SR: Role of endoscopic endoprostheses in proximal malignant biliary obstruction. J Hepatobiliary Pancreat Surg 8: 118-123, 2001.

7. Hameed A, Pang T, Chiou J, Pleass H, Lam V, Hollands M, Johnston E, Richardson A and Yuen L: Percutaneous vs. endoscopic pre-operative biliary drainage in hilar cholangiocarcinoma-A systematic review and meta-analysis. HPB (Oxford) 18: 400-410, 2016

8. Matsumoto K, Takeda Y, Onoyama T, Kawata S, Kurumi H, Koda H, Yamashita T and Isomoto H: Endoscopic treatment for distal malignant biliary obstruction. Ann Transl Med 5: 190, 2017.

9. Wiggers JK, Groot KB, Coelen RJ, Doussot A, van Dieren S, Rauws EA, Schattner MA, van Lienden KP, Brown KT, Besselink MG, et al: Percutaneous preoperative biliary drainage for resectable perihilar cholangiocarcinoma: No association with survival and no increase in seeding metastases. Ann Surg Oncol 22 (Suppl 3): S1156-S1163, 2015.

10. Stang A: Critical evaluation of the newcastle-ottawa scale for the assessment of the quality of nonrandomized studies in meta-analyses. Eur J Epidemiol 25: 603-605, 2010.

11. Higuchi R, Yazawa T, Uemura S, Izumo W, Chaudhary RJ, Furukawa T and Yamamoto M: ENBD is associated with decreased tumor dissemination compared to PTBD in perihilar cholangiocarcinoma. J Gastrointest Surg 21: 1506-1514, 2017.

12. Hirano S, Tanaka E, Tsuchikawa T, Matsumoto J, Kawakami H, Nakamura T, Kurashima Y, Ebihara Y and Shichinohe T: Oncological benefit of preoperative endoscopic biliary drainage in patients with hilar cholangiocarcinoma. J Hepatobiliary Pancreat Sci 21: 533-540, 2014.

13. Hwang S, Song GW, Ha TY, Lee YJ, Kim KH, Ahn CS, Sung KB, Ko GY, Kim MH, Lee SK, et al: Oncological benefit of preoperative endoscopic biliary drainage in patients with hilar cholangiocarcinoma. World J Surg 36: 379-385, 2012.

14. Kawakami H, Kuwatani M, Onodera M, Haba S, Eto K, Ehir N, Yamato H, Kudo T, Tanaka E, Hirano S, et al: Endoscopic nasobiliary drainage is the most suitable preoperative biliary drainage method in the management of patients with hilar cholangiocarcinoma. J Gastroenterol 46: 242-248, 2011.

15. Komaya K, Ebata T, Fukami Y, Sakamoto E, Miyake H, Takara D, Wakai K and Nagino M; Nagoya Surgical Oncology Group: Percutaneous biliary drainage is oncologically inferior to endoscopic drainage: A propensity score matching analysis in resectable distal cholangiocarcinoma. J Gastroenterol 51: 608-619, 2016.

16. Komaya K, Ebata T, Yokoyama Y, Igami T, Sugawara G, Mizuno T, Yamaguchi J and Nagino M: Verification of the oncologic inferiority of percutaneous biliary drainage to endoscopic drainage: A propensity score matching analysis of resectable perihilar cholangiocarcinoma. Surgery 161: 394-404, 2017.

17. Miura F, Sano K, Wada K, Shibuya M, Ikeda Y, Takahashi K, Kainuma M, Kawamura S, Hayano K and Takada T: Prognostic impact of type of preoperative biliary drainage in patients with distal cholangiocarcinoma. Am J Surg 214: 256-261, 2017.

18. Murakami Y, Uemura K, Hashimoto Y, Kondo N, Nakagawa N, Sasaki H, Hatano N, Kohmo T and Sueda T: Does preoperative biliary drainage compromise the long-term survival of patients with pancreatic head carcinoma? J Surg Oncol 111: 270-276, 2015 . 
19. Uemura K, Murakami Y, Satoi S, Sho M, Motoi F, Kawai M, Matsumoto I, Honda G, Kurata M, Yanagimoto H, et al: Impact of preoperative biliary drainage on long-term survival in resected pancreatic ductal adenocarcinoma: A multicenter observational study. Ann Surg Oncol 22 (Suppl 3): S1238-S1246, 2015.

20. Manzotti C, Audisio RA and Pratesi G: Importance of orthotopic implantation for human tumors as model systems: Relevance to metastasis and invasion. Clin Exp Metastasis 11: 5-14, 1993.

21. Tempero MA, Malafa MP, Al-Hawary M, Asbun H, Bain A, Behrman SW, Benson AI III, Binder E, Cardin DB, Cha C, et al: Pancreatic adenocarcinoma, version 2.2017, NCCN clinical practice guidelines in oncology. J Natl Compr Canc Netw 15: 1028-1061, 2017

22. Celotti A, Solaini L, Montori G, Coccolini F, Tognali D and Baiocchi G: Preoperative biliary drainage in hilar cholangiocarcinoma: Systematic review and meta-analysis. Eur J Surg Oncol 43: 1628-1635, 2017.

23. Mansour JC, Aloia TA, Crane CH, Heimbach JK, Nagino M and Vauthey JN: Hilar cholangiocarcinoma: Expert consensus statement. HPB (Oxford) 17: 691-699, 2015.

24. Banales JM, Cardinale V, Carpino G, Marzioni M, Andersen JB, Invernizzi P, Lind GE, Folseraas T, Forbes SJ, Fouassier L, et al: Expert consensus document: Cholangiocarcinoma: Current knowledge and future perspectives consensus statement from the European network for the study of cholangiocarcinoma (ENS-CCA). Nat Rev Gastroenterol Hepatol 13: 261-280, 2016.

25. Rerknimitr R, Angsuwatcharakon P, Ratanachu-ek T, Khor CJ, Ponnudurai R, Moon JH, Seo DW, Pantongrag-Brown L, Sangchan A, Pisespongsa P, et al: Asia-Pacific consensus recommendations for endoscopic and interventional management of hilar cholangiocarcinoma. J Gastroenterol Hepatol 28: 593-607, 2013.
26. Al MA, Menahem B, Fohlen A, Dupont B, Alves A, Launoy G and Lubrano J: Preoperative biliary drainage in patients with resectable perihilar cholangiocarcinoma: Is percutaneous transhepatic biliary drainage safer and more effective than endoscopic biliary drainage? A meta-analysis. J Vasc Interv Radiol 28: 576-582, 2017.

27. Miyazaki M, Yoshitomi H, Miyakawa S, Uesaka K, Unno M, Endo I, Ota T, Ohtsuka M, Kinoshita H, Shimada K, et al: Clinical practice guidelines for the management of biliary tract cancers 2015: The 2nd english edition. J Hepatobiliary Pancreat Sci 22: 249-273, 2015.

28. Morano WF, Shaikh MF, Gleeson EM, Galvez A, Khalili M, Lieb J, Renza-Stingone EP and Bowne WB: Reconstruction options following pancreaticoduodenectomy after Roux-en-Y gastric bypass: A systematic review. World J Surg Oncol 16: 168, 2018.

29. Strom TJ, Klapman JB, Springett GM, Meredith KL, Hoffe SE, Choi J, Hodul P, Malafa MP and Shridhar R: Comparative long-term outcomes of upfront resected pancreatic carcinoma after preoperative biliary drainage. Surg Endosc 29: 3273-3281, 2015.

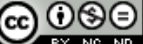

\footnotetext{
This work is licensed under a Creative Commons Attribution-NonCommercial-NoDerivatives 4.0 International (CC BY-NC-ND 4.0) License.
} 